\title{
Medical use of marijuana
}

\author{
Kinga K. Borowicz ${ }_{\text {ABCDEFG }}^{1,2}$ Paulina Kaczmarska ${ }_{\text {ABCDEFG}}$, Szalewska Barbara ${ }_{\text {ABCDEFG }}^{1}$ \\ ${ }^{1}$ Independent Unit of Experimental Neuropathophysiology, Department of Pathophysiology, Medi- \\ cal University of Lublin \\ ${ }^{2}$ The University of Vincent Pol in Lublin
}

\begin{abstract}
Summary
There are lot of myths about effects of marijuana. On one hand, it is considered as a stimulant with addictive potential. On the other hand, some beneficial medical effects of marijuana and cannabinoids have been reported lately. In the present study, we summarize the use of the drug and its derivative in the treatment of chronic pain, AIDS, multiple sclerosis, glaucoma, inflammatory bowel diseases, and other types of inflammation. Marijuana is rich in around 400 chemical compounds, 60 of which belong to the group of cannabinoids, the main one being delta-9-tetrahydrocannabinol (THC). The two main distinguished types of cannabinoid receptors are: CB1R and CB2R. The first one is believed to mediate psychoactive action, while the second one may be responsible for anti-inflammatory and other therapeutic effects of cannabis. In every case of medical use of marijuana and its derivatives the risk/benefit ratio should be individually considered.
\end{abstract}

Key words: marijuana, cannabis, delta-9-tetrahydrocannabinol (THC)

\section{Introduction}

Cultivation of the planting Cannabis sativa dates back many years ago. It was used to relieve pain in ancient times, even there are reports in discovering that 3000-year-old Egyptian mummies contained little amounts of THC.

Nowadays marijuana is one of the most popular drugs in the United States. Last time it started to be in the media spotlight because of loudly dispute over legalization marijuana for medical purposes. Actually, where access to marijuana is legal, it is mainly recommended for treating chronic diseases including: nausea (especially during chemotherapy), chronic pain, Crohn's disease, glaucoma, AIDS, multiple sclerosis, epilepsy, arthritis, migraines.

Why does it remain such a controversial subject? What if this medicine can be effective for patients who are not successfully treated in other ways and for them it is the last chance to relieve their suffering?

In this article we will take a look how does marijuana work to treat these conditions, and consider benefits and drawbacks of using marijuana in different medical conditions.

\footnotetext{
How does marijuana work in human body?

Marijuana plants contain 400 different chemicals, 60 of which are named cannabinoids. Main compound which have the biggest importance of influence in human body is delta-9-tetrahydrocannabinol (THC) and is known especially by its impact on short-term memory [1].
}

There are different ways, in which marijuana can be taken and each way determines different amount of substances are transferred into bloodstream. The biggest transmission of THC is by using hashish oil 15-30\% (sometimes up to 65\%) is available in the body, second place takes smoking marijuana in cigarette commonly known as joints - 6-20\% THC (60-200 mg/joint, over $300 \mathrm{mg}$ if laced with hashish oil), less percentage is transmitted by food intake for example cakes $10-20 \%$ THC or in mixing tobacco cigarettes with marijuana 1-3\% THC ( $\sim 10 \mathrm{mg} /$ reefer) [2]. The most common way of taking marijuana is smoking. This is the easiest and fastest way to pass through all substances to the bloodstream and throughout the body. By oral intake the concentration of the substances in blood is less than it reaches when smoked.

Actually, there are two main types of cannabinoids receptors: CB1R and CB2R [3]. CB1R - are the most numerous $G$ protein-coupled receptors in the brain, and considered as pivotal in psychotropic action of marijuana. Its activation via $\mathrm{Gi} / \mathrm{o}$ modulates voltagegated $\mathrm{K}^{+}$and $\mathrm{Ca}^{2+}$ conductance, resulting in decrease on neurotransmitter release: GABA and glutamate. It is activated: by the endocannabinoid neurotransmitters anandamide and 2-arachidonoyl glyceride (2-AG); by plant cannabinoids, such as the compound THC, an active ingredient of the psychoactive drug cannabis; and by synthetic analogues of THC, such as dronabinol. CB2R also conduct signals via $\mathrm{Gi} / \mathrm{o}$ and they were found in brain cells, mainly astrocytes, and cells of immune system. They seem to be responsible for anti-inflammatory and potential therapeutic effects of cannabis. 


\section{Beneficial uses}

\section{Lung cancer and oncology}

Lung cancer is one of the most frequent cancers with in high-mortality rate. Each year it takes its toll equally affecting men and women. Treatment is mainly based on chemotherapy, but there is one type of lung cancer, which is drug-resistant: non-small cell carcinoma (NSCLC) [4].

According to research performed at Harvard University, it reveals that marijuana contains an active ingredient, which has the ability to decrease tumor growth in lung cancer and significantly reduces possibility to spread metastases.

Preet [5] showed in her study that both CB1 and $\mathrm{CB} 2$ receptors are responsible for this efficacy, and they can be also activated by end cannabinoids and medical derivatives of THC. These receptors have been shown to be over-expressed in different cancers localized in the skin, lungs and breasts. When activated, they inhibit epidermal growth factor receptor (EGFR), which is over-expressed in NSCLC. That makes marijuana possibly a beacon of hope for patients who are suffering for this type of tumor.

Furthermore, cannabinoids, despite their anti-tumorigenic action, can attenuate other symptoms connected with oncological states. It reduces nausea and vomiting, which commonly occur during chemotherapy and it can be troublesome to be treated by anti-vomiting pills.

In terminal stages of the disease cancer is often accompanied by cachexia. The solution can be another peculiar phenomenon associated with taking marijuana. Cannabinoid receptor activation in the hypothalamic hunger centre increases food intake and results in weight gain.

\section{Glaucoma}

Another promising usage of marijuana is treatment of glaucoma. This condition by increased intraocular pressure gradually destroys the optic nerve and leads to loss of vision, being one of main causes of blindness in the world. The first mention in the world literature about usage of marijuana as an eye medication was found in the ancient Egyptian papyrus [6].

The mechanism of action of marijuana in glaucoma is still unknown. There is a suspicion that it is mediated by CB2 receptor-induced improvement of retinal circulation $[7,9]$. The main advantage of such a treatment is that it lowers intraocular pressure without any serious adverse effects. Incidentally, anxiety, psychoactive and some cardiovascular effects after either smoked or orally taken THC $[8,10]$.

Good results in decreasing intra-ocular pressure were achieved by the combination of timolol eye drops and extract of cannabis, which effects seem to be complementary [11].

\section{AIDS}

The HIV virus actively multiplies, infects and kills CD4+T lymphocytes, considered as crucial infection fighters. At present, there is no cure for HIV or AIDS, but some medications are effective in delaying the onset of disease and its complications. In the beginning, infection does not give specific symptoms. With weakening of the immune system, a full picture of AIDS develops and is manifested by fever and sweats, herpes infections, lack of energy, skin rashes or flaky skin, short-term memory loss, and weight loss often leading to cachexia. Marijuana has been used in the treatment of HIV-induced cachexia since 1986. Moreover, Food and Drug Administration approved use of THC-derivative Dronabinol to treat this condition [12].

Up to $40 \%$ of HIV infections are related with cognitive impairment and dementia. The effective treatment may be troublesome since most medications do not cross the blood-brain barrier. According to data from Harvard University cannabinoids can permeate this barrier and protect the brain from HIV-related neurotoxic protein Gp120. Avraham et al. [13] indicated that cannabinoid AM2421, which acts via CB2R, may protect neuronal stem cells. Experiments performed on mice confirmed also positive effect of cannabinoids on neurogenesis. Other investigations showed that CB2R attenuate CXCR4-tropic HIV infection. Receptors (CB1R and mostly CB2R) and HIV co-receptors (CXCR4 and CCR5), which have similar structure, can influence each other and change the course of disease.

Agonists of CB2R were reported to change the cytoskeletal compound of lymphocytes, which impeded virus transmit between CD4+ lymphocytes and inhibited production of inflammatory cytokines in CD4+ cells. HIV viruses with preferential tropism to CXCR4 are considered to cause more rapid development of AIDS. It seems that usage of cannabinoids might be pivotal in setting down progress of AIDS by inhibition of CXCR4-related transformation of lymphocytes [14].

\section{Possible use in inflammation}

The effect of cannabinoids on the immune system has been a subject of research since 1964 when the major psychoactive substance THC was clearly described [15]. It has been used for medical purposes for years and its anti-inflammatory activity has been alluded in Chinese medicine ancient handbooks as an effective drug in rheumatism therapy. The effect of THC on immune homeostasis is mediated through CB2Rs, which are expressed predominantly in the periphery, particularly on lymphoid cells and organs [16]. Cannabinoid agonists were reported to influence proliferation of lymphocytes $\mathrm{T}$, lymphocytes $\mathrm{B}$, macrophages, and modulate production of cytokines and antibodies [17, $18,19,20,21]$. Clinical observations seem to confirm immunomodulatory effects of cannabis - a shift of the cytokine balance toward the T- helper cell type 2 profile 
and suppression of cell-mediated immunity were observed in cannabis users [22].

Growing morbidity of immune diseases observed recently especially in more developed countries and insufficient effectiveness of available therapeutic methods, has increased the interest over alternative methods. Wide distribution of cannabinoid receptors in the immune system suggests that the endocannabinoid receptors are a new target for anti-inflammatory interventions. We would like to review the current studies which have focused on the use of cannabinoids in the treatment of inflammatory bowel disease and multiple sclerosis.

\section{Inflammatory Bowel Disease}

Inflammatory Bowel Disease (IBD) is a group of inflammatory conditions of gastrointestinal tract and commonly refers to ulcerative colitis (UC) and Crohn's disease (CD). Both diseases may present such symptoms as abdominal pain, vomiting, diarrhoea, rectal bleeding, severe internal cramps/muscle spasms in the region of the pelvis and weight loss. Experiments in humans revealed increased expression of CBRs and higher endocannabinoid levels in intestinal biopsies of patients with IBD [23]. First evaluation of cannabis use in CD performed by Naftali et al. [24] in retrospective, observational study showed the significant reduction of need for other medications among 21 out of 30 monitored patients. Naftali et al. [25] also presented a placebo-controlled prospective study in 21 patients with $\mathrm{CD}$ unresponsive to standard IBD, which demonstrate that an 8-week treatment with THC-rich cannabis caused an improvement in $90 \%$ of patients without producing significant side effects. A pilot prospective study performed by Lahat et al. [26] showed improvement of quality of life, gain of weight and rise in BMI among patients after three months of treatment. However, Storr at al. [27] in regression analysis drew attention that the use of cannabis can be a strong predictor of requiring surgery in patients with CD. Spain study of Garcia-Planella [28] about strategies of self-treatment indicated that among 214 patients with IBM there were $10 \%$ who admitted anonymously to cannabis use in order to alleviate the symptoms. Common use of cannabis among IBD patients is also confirmed by Lal [29] encouraging to further research of its use in the therapy of bowel inflammation.

\section{Multiple sclerosis}

Multiple sclerosis (MS) is an demyelinising autoimmune inflammatory disease of CNS, which affects 50-100 in 100000 people living in temperate climate. Symptoms of MS differ depending on the location of lesions within the nervous system, but commonly include muscle stiffness and spasticity, loss of sensitivity or changes in sensation, tremor, fatigue, pain, incontinence and sexual dysfunction, ataxia and visual problems. Spasticity is one of the most disabling symptoms and has the greatest impact on patient well-being and quality of life. Available traditional drug therapies for spasticity appear to have limited benefit and are often associated with serious side effects. Seeking new therapeutical solution, Multiple Sclerosis and Extract of Cannabis (MUSEC) trial evaluated the effect of cannabinoids on symptoms such as spasticity, pain and sleep quality at 279 patients at double-blind, placebo controlled study showing self-reported relief in muscle stiffness almost twice as high with patients treated by oral cannabis extract than with placebo [30]. Similar outcome was observed by Corey-Bloom [31] among $30 \mathrm{MS}$ patients with treatment-resistant spasticity. Cannabinoids were also considered as effective new agents for the treatment of symptomatic spasticity in MS in randomized control trial made by Collin [32]. Delta-9-THC/CBD [nabiximol, Sativex ${ }^{\otimes}$ is approved in a number of countries, including Germany and the UK, as an add-on treatment for spasticity in the course of MS in patients, who have not responded adequately to other antispastic treatment and who have demonstrated clinically significant improvement during an initial trial of therapy [33]. In a new study presented by Flachenecker [34] real-life observational data on clinical use of nabiximol were compared with formal clinical trials. The main conclusion was that significant effectiveness of nabiximol makes it an important treatment option for resistant multiple sclerosis-associated spasticity in clinical practice. Adverse events were reported in each aforementioned study, however, THC/CBD combinations were generally considered to be well-tolerated.

Most patients suffering from MS develop lower urinary tract syndrome (LUTS), which can significantly reduce quality of life. Treatment based on anticholinergics and intermittent self-catheterizations is limited only to early stage of illness. An open-label pilot study conducted by Brady et al. [35] showed that 15 out of 21 patients with MS-related vexatious and standard therapy-resistant LUTS, who completed 16-week therapy of THC/CBD, demonstrated improvement in urinary symptoms. Both self- and outpatient assessments (laboratory tests, cystometry, questionnaires) revealed significant decrease in urinary urgency, the number and volume of incontinence episodes, frequency and nocturia. Most patients have experienced only mild side effects. However, further detailed studies are required to prove efficacy of cannabinoid treatment in LUTS.

Recent study of Langford [36] examined the effect of combined therapy of THC/CBD oromucosal spray with the existing treatment regimen in MS-related neuropathic pain. However, the author did not directly confirm an analgesic effect of cannabinoids in this condition [36]. Similarly, a randomised, placebo-controlled trial presented by Zajicek [37] did not support a role of THC in slowing progression or modification of MS course.

Report of the Guideline Development Subcommittee of the American Academy of Neurology 
[38] presenting evidence-based recommendations for complementary and alternative medicines in MS gives recommendations to use oral and oromucosal cannabis extract for reducing spasticity and pain.

\section{Drawbacks and side effects}

Despite of many beneficial physiological aspects, use of medical marijuana may also cause some negative adverse effects. From the psychiatric point of view, cannabis brings more harm than benefits. It is well known that marijuana may lead to addiction, especially when is used for a longer time. What is interesting, it can exert either sedative or anxiogenic effect, depending on inter-individual susceptibility. Some investigations showed that marijuana can also trigger panic attacks.

Moreover, cannabinoids have influence on mood. Tests performed on patients with bipolar disorder revealed that the frequency of manic and depressive mood swings have increased. Although in the group of people suffering from depression marijuana proved some antidepressant properties, its daily usage may decrease mood level.

Some studies underline that cannabinoids can trigger schizophrenia and exacerbate psychotic symptoms, especially in youths. Investigations on group of Swedish soldiers indicated that even one trial of smoking marijuana increases twice susceptibility for developing schizophrenia in comparison to non-smokers.

Other adverse effects of cannabinoids are: impairment of short-term memory, higher susceptibility for developing pulmonary disorders, gastrotoxic effects like nausea, vomiting, diarrhea [39].

\section{Conclusions}

Cannabinoids may have some beneficial analgesis, antispastic or anti-inflammatory effects, especially in standard therapy-resistant conditions. However, possible neuropsychological adverse effects should not be underestimated and benefit/risk ratio should be assesses individually in every case of medical marijuana use.

\section{References:}

1. Pacher P, Bátkai S, Kunos G. The endocannabinoid system as an emerging target of pharmacotherapy. Pharmacological Reviews. 2006; 58: 389-462.

2. Ashton C.H. Pharmacology and effects of cannabis: a brief review. The British Journal of Psychiatry. 2001; 178: 101-106.

3. Preet A, Qamri Z, Nasser M.W, Prasad A, Shilo K, Zou X, Groopman J.E, Ganju R.K. Cannabinoid receptors, $\mathrm{CB} 1$ and $\mathrm{CB} 2$, as novel targets for inhibition of non-small cell lung cancer growth and metastasis. Cancer Prev. Res. (Phila). 2011; 4: 65-75.

4. Pertwee R.G. The diverse $\mathrm{CB} 1$ and $\mathrm{CB} 2$ receptor pharmacology of three plant cannabinoids: $\Delta 9$-tetrahydrocannabinol, cannabidiol and $\Delta 9$-tetrahydrocannabivarin. British Journal of Pharmacology. 2008; 153 : 199-215.
5. American Association for Cancer Research. Marijuana cuts lung cancer tumor growth in half. Study shows. Science Daily. 2007.

6. Mathre M.L. Cannabis in medical practice. Legal, historical and pharmacological overview of the therapeutic use of marijuana. Jefferson, N.C. (Ed.), McFarland \& Co.1997.

7. Järvinen T, Pate D.W, Laine K. Cannabinoids in the treatment of glaucoma. Pharmacology \& Therapeutics. 2002; 95: 203-220.

8. Tomida I, Azuara-Blanco A, House H, Flint M, Pertwee R.G, Robson P.J. Effect of sublingual application of cannabinoids on intraocular pressure: a pilot study. J. Glaucoma. 2006; 15: 349-353.

9. Merritt J.C, Crawford W.J, Alexander P.C, Anduze A.L, Gelbart S.S. Effect of marihuana on intraocular and blood pressure in glaucoma. Ophthalmology. 1980; 87: 222-228.

10. West M.E, Lockhart A.B. The treatment of glaucoma using a non-psychoactive preparation of Cannabis sativa. West. Indian Med. J. 1978; 27: 16-25.

11. Plange N, Arend K.O, Kaup M, Doehmen B, Adams H, Hendricks S, Cordes A, Huth J, Sponsel W.E, Remky A. Dronabinol and retinal hemodynamics in humans. Am. J. Ophthalmol. 2007; 143: 173-174.

12. Lutge E.E, Gray A, Siegfried N. The medical use of cannabis for reducing morbidity and mortality in patients with HIV/AIDS. Cochrane Database Syst. Rev. 2013; 4: 1-47.

13. Costantino C.M, Gupta A, Yewdall A.W, Dale B.M, Devi L.A, Chen B.K. Cannabinoid receptor 2-mediated attenuation of CXCR4-tropic HIV infection in primary CD4+ T cells. PLoS One. 2012; 7: 339-361.

14. Avraham H.K, Jiang S, Fu Y, Rockenstein E, Makriyanni A, Zvonok A, Masliah E, Avraham S. The cannabinoid CB2 receptor agonist AM1241 enhances neurogenesis in GFAP/Gp120 transgenic mice displaying deficits in neurogenesis. British Journal of Pharmacology. 2014 ; 171: 468-479.

15. Gaoni Y, Mechoulam R. Isolation, structure elucidation and partial synthesis of an active constituent of hashish. J. Am. Chem. Soc. 1964; 68: 1646-1647.

16. Galiegue S, Mary S, Marchand J, Dussossoy D, Carriere D. Carayon P, Bouaboula M, Shire D, Le Fur G, Casellas P. Expression of central and peripheral cannabinoid receptors in human immune tissues and leukocyte subpopulations. Eur. J. Biochem. 1995; 232: 54-61. 17. Klein T.W, Newton C, Friedman H. Cannabinoid receptors and immunity. Immunol. Today. 1998; 19: 373-381.

18. Klein T.W, Lane B, Newton C.A, Friedman H. The cannabinoid system and cytokine network. Proc. Soc. Exp. Biol. Med. 2000; 225: 1-8.

19. Klein T.W. Cannabinoid-based drugs as anti-inflammatory therapeutics. Nat. Rev. Immunol. 2005; 5: 400-411.

20. Parolaro D. Presence and functional regulation of cannabinoid receptors in immune cells. Life Sci. 1999; 65: 637-644. 
21. Croxford J.L, Yamamura T. Cannabinoids and the immune system: potential for the treatment of inflammatory diseases? J. Neuroimmunol. 2005; 166: 3-18. 22. Pacifici R, Zuccaro P, Pichini S, Roset P.N, Poudevida S, Farre M, Segura J, De la Torre R. 2003. Modulation of the immune system in cannabis users. J. Am. Med. Assoc. 2003; 289: 1929-1931.

23. Marquéz L, Suárez J, Iglesias M, Bermudez-Silva F.J, Rodríguez de Fonseca F, Andreu M. Ulcerative colitis induces changes on the expression of the endocannabinoid system in the human colonic tissue. PLoS One. 2009; 4: 68-93.

24. Naftali T, Lev L.B, Yablecovitch D, Half E, Konikoff F.M. Treatment of Crohn's disease with cannabis: an observational study. Isr. Med. Assoc. J. 2011; 13: 455-458. 25. Naftali T, Bar-Lev Schleider L, Dotan I, Lansky E.P, Sklerovsky-Benjaminov F, Konikoff F.M. Cannabis induces a clinical response in patients with Crohn's disease: a prospective placebo-controlled study. Clin. Gastroenterol. Hepatol. 2013; 11: 1276-1280.

26. Lahat A, Lang A, Ben-Horin S. Impact of cannabis treatment on the quality of life, weight and clinical disease activity in inflammatory bowel disease patients: a pilot prospective study department of Gastroenterology. Israel Digestion. 2012; 85: 1-8.

27. Storr M, Devlin S, Kaplan G.G, Panaccione R, Andrews C.N. Cannabis use provides symptom relief in patients with inflammatory bowel disease but is associated with worse disease prognosis in patients with Crohn's disease. Inflamm. Bowel Dis. 2014; 20: 472-480.

28. Garcia-Planella E, Marin L, Domenech E, Bernal I, Manosa M, Zabana Y, Gassull M.A. Use of complementary and alternative medicine and drug abusein patients with inflammatory bowel disease. Med. Clin. (Barc.). 2007; 128: 45-48.

29. Lal S, Prasad N, Ryan M, Tangri S, Silverberg M.S, Gordon A, Steinhart H. Cannabis use amongst patients with inflammatory bowel disease. Eur. J. Gastroenterol. Hepatol. 2011; 23: 891-896.

30. Zajicek J.P, Hobart J.C, Slade A, Barnes D, Mattison P.G. Multiple sclerosis and extract of cannabis: results of the MUSEC trial. J. Neurol. Neurosurg. Psychiatry. 2012; 83: 1125-1132.

31. Corey-Bloom J, Wolfson T, Gamst A, Jin S, Marcotte T.D, Bentley H, Gouaux B. Smoked cannabis for spasticity in multiple sclerosis: a randomized, placebocontrolled trial. Canadian Medical Association Journal. 2012; 184: 1143-1150.

32. Collin C, Davies P, Mutiboko I.K, Ratcliffe S. Randomized controlled trial of cannabis-based medicine in spasticity caused by multiple sclerosis. Eur J Neurol. 2007; 14: 290-296.

33. Syed Y.Y, McKeage K, Scott L.J. Delta-9-tetrahydrocannabinol/cannabidiol (Sativex):

a review of its use in patients with moderate to severe spasticity due to multiple sclerosis. Drugs. 2014; 74 : 563-578.
34. Flachenecker P, Henze T, Zettl U.K. Nabiximols (THC/CBD oromucosal spray, Sativex) in clinical practice - results of a multicenter, non-interventional study (MOVE 2) in patients with multiple sclerosis spasticity. Eur. Neurol. 2014; 71: 271-279.

35. Brady C.M, DasGupta R. Dalton C, Wiseman O.J, Berkley K.J, Fowler C.J. An open-label pilot study of cannabis-based extracts for bladder dysfunction in advanced multiple sclerosis. Mult. Scler. 2004; 10: 425433.

36. Langford R.M, Mares J, Novotna A, Vachova M, Novakova I, Notcutt W, Ratcliffe S.J. A double-blind, randomized, placebo-controlled, parallel-group study of $\mathrm{THC} / \mathrm{CBD}$ oromucosal spray in combination with the existing treatment regimen, in the relief of central neuropathic pain in patients with multiple sclerosis. Neurol. 2013; 260: 984-997.

37. Zajicek J, Ball S, Wright D, Vickery J, Nunn A, Miller D, Gomez Cano M, McManus D, Mallik S, Hobart J. CUPID investigator group. Effect of dronabinol on progression in progressive multiple sclerosis (CUPID): a randomised, placebo-controlled trial. Lancet Neurol. 2013; 12: 857-865.

38. Yadavm V, Bever C. Jr, Bowen J, Bowling A, Weinstock-Guttman B, Cameron M, Bourdette D, Gronseth G.S, Narayanaswami P. Summary of evidence-based guideline: complementary and alternative medicine in multiple sclerosis: report of the guideline development subcommittee of the American Academy of Neurology. Neurology. 2014; 82: 1083-1092.

39. McDonald A. Medical marijuana and the mind. Harvard Mental Health Letter. 2010; 26: 1-3.

\section{Correspondence address:}

Prof. Kinga K. Borowicz, M.D., Ph.D.

Independent Unit of Experimental Neuropathophysiology, Department of Pathophysiology, Medical University of Lublin

ul. Ceramiczna 1

20-150 Lublin

kingaborowicz@umlub.pl 